(ISW), Chronic Respiratory Disease Questionnaire (CRDQ), MRC Dyspnoea score (MRC) and COPD assessment test (CAT) were measured. Between group differences were compared using Mann-Whitney U or unpaired t-test.

Results Data are presented as median $\left(25^{\text {th }}, 75^{\text {th }}\right.$ centiles), and summarised in Abstract P37 table 1. 130 COPD patients from this cohort were taking either an ACE-I $(n=82)$, ARB $(n=45)$ or both $(n=3)$. The groups were matched for gender distribution and longterm oral corticosteroid use. Compared with the control COPD patients, those on ACE-I or ARB were older, had better $\mathrm{FEV}_{1} \%$ predicted but similar ISW, CRDQ, MRC and CAT. However, the patients receiving ACE-I or ARB had significantly higher fat free mass (FFM) and fat free mass index (FFMI).

Abstract P37 Table 1 Mean (SD) or median $\left(27^{\text {th }}, 75^{\text {th }}\right.$ centile). $p$ Values represent between group differences (Mann-Whitney or unpaired $\mathrm{t}$-test)

\begin{tabular}{lllr}
\hline & ARB/ACE-I & No ARB/ACE-I & p Value \\
\hline Age (years) & $71(64,78)$ & $67.6(9.8)$ & 0.004 \\
FEV 1 (\% predicted) & $44.5(32.3,60.8)$ & $39.0(26.0,58.5)$ & 0.007 \\
FFM $(\mathrm{kg})$ & $51.1(11.2)$ & $45.5(40.1,52.0)$ & $<0.001$ \\
FFMI $\left(\mathrm{kg} / \mathrm{m}^{2}\right)$ & $17.8(16.0,19.8)$ & $16.5(14.9,18.4)$ & $<0.001$ \\
ISWT $(\mathrm{m})$ & $140(60,250)$ & $160(80,280)$ & 0.10 \\
CRDQ & $71.5(55.8,91.0)$ & $68.0(56.0,87.0)$ & 0.45 \\
MRC & $4(3,5)$ & $4(3,5)$ & 0.79 \\
CAT & $23.0(8.0)$ & $22.0(7.0)$ & 0.76 \\
\hline
\end{tabular}

Conclusions In an unselected COPD cohort referred for pulmonary rehabilitation, patients on ACE-I or ARB appear to have increased muscle mass compared with those receiving neither drug. Future longitudinal studies and randomised controlled trials are required to further define the effect of ACE-I and ARB in COPD.

\section{P38 IS NUTRITIONAL STATUS NEGLECTED IN COPD PATIENTS ADMITTED TO HOSPITAL?}

doi:10.1136/thoraxjnl-2011-201054c.38

\section{Jones, J Suntharalingam. Royal United Hospital, Bath, UK}

Introduction and Objectives Targeting nutritional status is a key issue in COPD. Studies have shown increased mortality in patients with low BMI $^{1}$ which improves following weight gain. ${ }^{2}$ This study examines whether nutritional status is adequately assessed and acted upon in COPD patients admitted to a DGH.

Method Patients admitted to the RUH, Bath with a COPD exacerbation over a 4-month period were prospectively included. Case notes were reviewed to determine whether BMI had been documented. If a BMI wasn't documented, patients' height and weight was measured allowing calculation of BMI. Notes were also assessed for dietician referrals, nutritional supplement prescription and whether patients had their weight monitored. Length of stay (LOS) and in-hospital survival data were collected.

Results BMI was recorded in 25/51 of the patients included (mean age $74 \mathrm{yrs}, 47 \%$ male.) In $88 \%$ of cases BMI had been estimated not calculated. Of these, $11 / 25$ patients had had their BMI additionally calculated by the study investigators $-4 / 11$ patients had been estimated to have a normal BMI when in fact they were underweight. $13 / 51$ patients had a BMI $<18$. Patients with BMI $<18$ had a lower percentage predicted $\mathrm{FEV}_{1}(32 \%$ vs $52 \% \mathrm{p}=0.02)$ and a lower Urea level $(5.6 \mathrm{mmol} / \mathrm{l}$ vs $7.9 \mathrm{mmol} / \mathrm{l} \mathrm{p}=0.04)$. $1 / 13$ were referred to a dietician, $8 / 13$ were prescribed nutritional supplements and nutrition wasn't addressed in 4/14 patients. Only 4/14 patients had their weight monitored. Patients with a BMI $<18$ exhibited similar in-hospital mortality (15.4\% vs $18.4 \%$ ) but had a higher LOS (26.8 days vs 15.5 days $p=0.03$ ).

Conclusion BMI measurements were poorly recorded in patients admitted to hospital. Where BMI was recorded this was estimated, rather than calculated, leading to underreporting. Only $71 \%$ of patients with low BMIs received dietetic input or nutritional supplementation during their stay. Patients with a low BMI had a significantly longer LOS.

\section{REFERENCES}

1. Landbo C, et al. American Journal of Respiratory \& Critical Care Medicine 1999:160:1856-61.

2. Schols AMWJ, et al. American Journal of Respiratory \& Critical Care Medicine 1998; 157:1791-7.

\section{P39 NUTRITIONAL ASSESSMENTS IN COPD: THE RESPIRATORY NURSE PERSPECTIVE ON CURRENT PRACTICE ACROSS THE UK}

doi:10.1136/thoraxjnl-2011-201054c.39

J Annandale, C Kelly, R Sherrington. Association of Respiratory Nurse Specialists, London, UK

Background Low body mass index (BMI) and weight loss are associated with a poorer prognosis for patients with COPD but are potentially reversible. ${ }^{1}$ Nutritional assessments should be key part of patient management and respiratory nurses are in a good position to undertake these. Guidelines ${ }^{1}$ recommend referral to a dietician for those patients with an abnormal BMI $(<20$ or $>25)$ and those with a low BMI given nutritional supplements.

Methodology An electronic survey using closed ended questions was emailed to 533 respiratory nurses in the UK. 177 responses (33\%) were returned from across primary, secondary and community sectors. Those nurses not managing COPD patients were asked not to respond.

Results $88 \%$ reported using weight and BMI to assess patients, with $85 \%$ undertaking an assessment at least once or twice year. Only $32 \%$ used any further screening tool. $94 \%$ of nurses have access to a dietician and $85 \%$ of nurses are able to refer directly, but highlight long waiting times. Despite this, $54 \%$ refer less than half of patients they identify with an ongoing nutritional problem. $16 \%$ are unable to get nutritional supplements for their patients but, where available, $96 \%$ had access to a range of supplements. Reasons cited were the need for a dietician referral first and GPs reluctance to prescribe supplements. $65 \%$ reported not having any specific criteria for referral to a dietician and $87 \%$ felt a specific simple practical tool would help manage this group of patients. $42 \%$ felt overall that malnourished patients were managed poorly in their area (see Abstract P39 table 1).

\section{Abstract P39 Table 1}

\begin{tabular}{llll}
\hline How well do you feel malnourished patients are managed in you area? (\%) \\
\hline Very well & Well & Poorly & Very poorly \\
4.1 & 54.1 & 40 & 1.8
\end{tabular}

Discussion Respiratory nurses conduct nutritional assessments with COPD patients and the majority appear to have access to a dietician. Yet, despite this, referral to specialist dietetic services is low. This may be due to perceived lack of dietician services or long waiting times. Improved awareness, education and training among respiratory nurses regarding nutritional assessment together with improved access to dietetic services would seem to be priorities for the future in order to meet current recomendations. ${ }^{1}$ 